\title{
EXPERIMENTAL AND NUMERICAL ANALYSIS OF CRACK PROPAGATION IN LIGHT COMPOSITE MATERIALS UNDER DYNAMIC FRACTURING
}

Research and analysis of mechanical properties including crack propagation in a light composite material is currently very important because composite structures are gradually becoming an alternative material that allows a significant reduction in the weight of car parts. This leads to an increase in efficiency in transport vehicles. This article describes experimental as well as model analysis of damage to composite textiles during dynamic fracturing. The obtained information provides an approach to the complex problem of crack propagation in composite textiles intended for use in car seats. This is especially important from the point of view of safety, because during an accident a significant overload of the human body occurs and its kinetic energy can cause deformation of a breach in the composite textile. Therefore, identifying the direction of crack propagation is very important for the safety of passengers. Experimental studies have demonstrated that a dynamic breach is caused by the significant deformation of the tested sample. The distribution and direction of crack propagation in the sample was studied using a FEM model, based on the Griffith-Irwin criterion with nonlinear orthotropic properties of the composite textile.

Keywords: Light composite material, crack, FEM model, Irwin factor.

\section{Introduction}

The current trends and efforts in the development of components and systems, especially for vehicles, include their innovation leading to weight reduction. The main parameters of structural optimization are primarily dynamic and static strength and durability. They influence the mechanical properties (materials of construction, geometrical dimensions, shape), technological factors (quality, surface properties, nicks, welds and joints), loading conditions (load, climatic conditions, temperature, corrosion) and vibration [1]. Weight reduction is also very important. For this purpose light, energy-saving and recyclable materials that have the same or better parameters than standard materials are used. New composite structures have become the subject of interest. The optimal directional arrangements of fibres and the type and amount of the matrix for a given load have yet to be defined for these structures. Therefore, the research is focused on testing and analysis of alternative textile materials that are currently being used for the production of the frame constructions of car seats. The safety wall elements of the current seat design are preserved and the supporting metal or spring construction of the seat and backrest is replaced by an alternative low-weight composite textile reinforcement [2 and 3]. The problem lies mainly in the fact that this structural modification leads to a reduction in the weight of the seat frame construction, but the risk of deformation of the textile during an accident increases. The weight and body constitution directly affect the interaction of the seat, especially during impact [4 and 5]. A dynamic impact could lead to a break in alternative textiles which can be damaged. The main objective of this paper was to perform an experimental analysis and to construct a simulation model describing the distribution of the limit state and the rate of crack propagation in a hyper elastic composite with textile reinforcement. The crack occurs in the loaded material in the anchor points on the frame. Degradation may also occur due to the creep properties of the material. This can be caused by long-term acting forces (random loading by the human body, pre-stress of textile). It is very difficult to describe the course, direction and initiation of cracks in the composite textile and they are practically immeasurable. The rate of crack propagation and the characteristic force-elongation dependence can be experimentally determined using the Aramis measuring system, but it is not possible to describe the distribution of stress intensity, e.g. by the direction of the principal stress tensor. It is possible to a certain extent to describe the stress intensity using FEM model simulation based on mathematical theories that use Griffith-Irwin criteria.

\footnotetext{
* ${ }^{1}$ Michal Petru, ${ }^{2}$ Josef Broncek, ${ }^{3}$ Petr Lepsik, ${ }^{4}$ Ondrej Novak

${ }^{1}$ The Institute for Nanomaterials, Advanced Technologies and Innovation, Technical University of Liberec, Czech Republic

${ }^{2}$ Department of Design and Mechanical Elements, Faculty of Mechanical Engineering, University of Zilina, Slovakia

${ }^{3}$ Department of Design of Machine Elements and Mechanisms, Faculty of Mechanical Engineering, Technical University of Liberec, Czech Republic

${ }^{4}$ Department of Nonwovens and Nanofibrous materials, Faculty of Textile Engineering, Technical University of Liberec, Czech Republic

E-mail: michal.petru@tul.cz
} 


\section{Materials and methods}

\subsection{Experimental measurements}

Test samples of a hyper elastic composite reinforcement consist of two different layers - woven with orthotropic properties and a hyper elastic coating. A combination of these structures causes changes in the mechanical properties - especially changes to the viscoelastic and hyper elastic parameters. The physical properties of the tested samples are given in Table 1. Testing equipment for the drop test with an impact velocity of $8 \mathrm{~m} . \mathrm{s}^{-1}$ was built for the experiment. The equipment comprises jaws for mounting the composite textile sample, sensors for acceleration, displacement, force and the Aramis system. This system uses two high speed cameras for stereoscopic visualization. The layout of the experiment is illustrated in Fig. 1 and the time course of the dynamically loaded composite textile is shown in Fig. 2. The obtained data were evaluated using the DEWESoft 7.0 software. The dimensions of the composite textile sample were 150x150x1.3 mm.
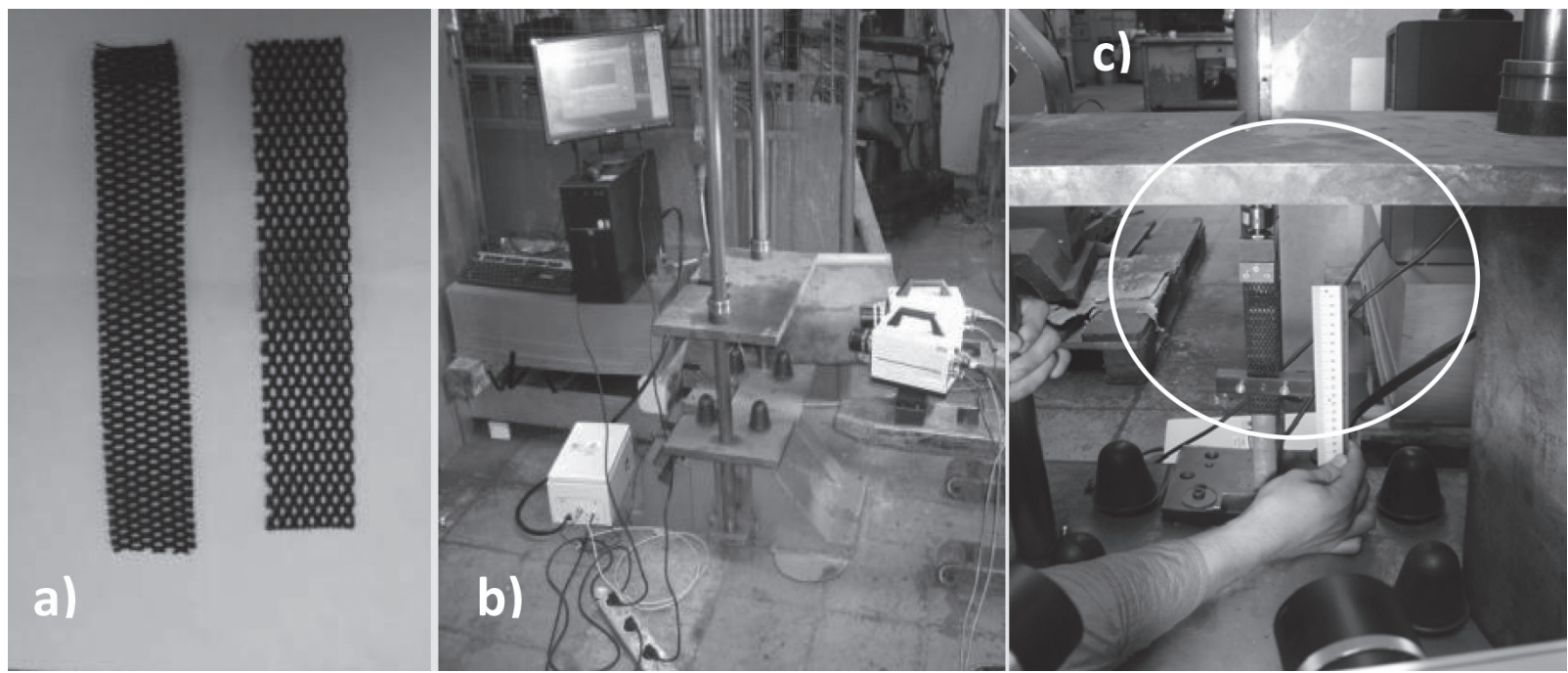

Fig. 1 Experimental measurement of a dynamically loaded sample: a) composite textile - longitudinal and transverse direction, b) arrangement of the experimental device, c) close up of sample placement
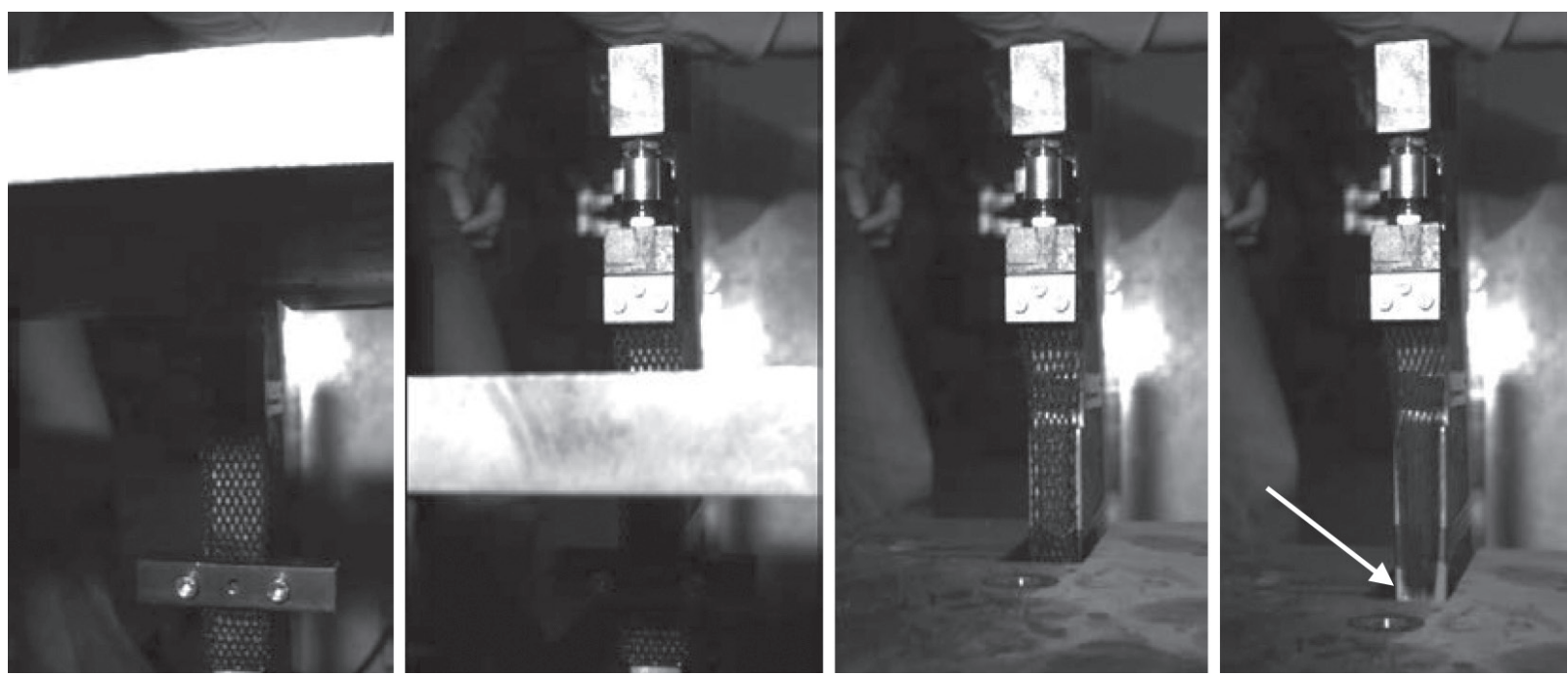

Fig. 2 The time course of dynamically loaded composite textile: Time (0-60 ms) 
Mechanical properties of samples compressed to $50 \%$ deformation

Table 1

\begin{tabular}{|l|l|l|}
\hline Specific properties & Value & Unit \\
\hline Density & 1052 & $\mathrm{~kg} \cdot \mathrm{m}^{-3}$ \\
\hline Strain at yield & 1800 & $\mathrm{MPa}$ \\
\hline $\begin{array}{l}\text { Tensile creep modulus } \\
(0.5 \% 1000 \text { hrs. })\end{array}$ & 1100 & $\mathrm{MPa}$ \\
\hline Modulus of elasticity & 112 & $\mathrm{MPa}$ \\
\hline Ultimate bending strength & 2700 & $\mathrm{MPa}$ \\
\hline Tensile strength & 33 & $\mathrm{MPa}$ \\
\hline $\begin{array}{l}\text { Fatigue limit under alternating bending stress } \\
(10 \mathrm{e}+7 \text { cycles })\end{array}$ & $0.24-0.4$ & $\mathrm{~min}$ \\
\hline $\begin{array}{l}\text { The coefficient of sliding friction compared to } \\
\text { steel in a dry environment }\end{array}$ & 1.7 & $\mathrm{J.g} \cdot{ }^{-\mathrm{K}}$ \\
\hline Specific heat capacity & 235 & ${ }^{\circ} \mathrm{C}$ \\
\hline $\begin{array}{l}\text { Tensile creep modulus } \\
(0.5 \% 1000 \text { hrs. })\end{array}$ & $\begin{array}{l}1050- \\
1250\end{array}$ & $\mathrm{~kg} . \mathrm{m}^{-3}$ \\
\hline
\end{tabular}

\subsection{Mathematic theory of cracks}

Integral parameters of the crack will be introduced to describe the crack propagation and its instability. These parameters will then be compared with the experimentally identified critical values. The Irwin factor $K$ [6, 7 and 8] can be used for this purpose. It is based on energy of stress intensity where the zone of stress intensity factor (1-2) and the field of shifts in nonlinear behaviour in the crack are used. The Irwin factor can be used to describe the crack in the isotropic and anisotropic materials. The sample of the hyper elastic orthotropic reinforcement has properties that are different in machine direction as well as cross direction [2 and 3], but during dynamic tearing they have a similar course which can be described by the multiplying with a constant. This may be due to the fact that such a structure under dynamic failure is significantly stiffer. In this case a volume strain occurs, which is manifested by a deformation of the plastic. The application of Irwin factor distribution on the tested sample is shown in (Fig. 3).

$\sigma_{i j}(r, \Psi)=\left(r^{-1 / 2}\right) \cdot\left[K_{I} f(\psi)+K_{I I} g_{i j}(\psi)\right]$

$u_{i}(r, \Psi)=\left(\frac{r^{-1 / 2}}{G}\right) \cdot\left[K_{I} F_{i}(\psi)+K_{I I} G_{i}(\psi)\right]$

where $\sigma_{i j}$ is the Cauchy tensor of stress, $u_{i}$ is the vector of translation, $r, \psi$ are separated variables which describe the assumed direction of crack propagation (the assumption is $0<\psi<\pi / 2, a$ is a half length of crack edge (flaw) in a material, $r / a$ is a dimensionless parameter expressing the ratio of separated variables $r$, which describe the assumed direction of the crack propagation and a is a half length of crack edge (flaw) in a material, $K_{I}, K_{I I}$ is the determined factor of stress intensity, $f_{i j}$, $g_{i j}$ are nonzero functions of stress related to intensity factors $K_{I}$, $K_{I I}, G$ is a shear modulus of elasticity, $F_{i}, G_{i}$ are nonzero functions describing the field of translations related to intensity factors $K_{I}$, $K_{I I}, t_{\text {crack }}$ is the time of crack propagation, $t_{\text {init }}$ is the time of crack initiation $\left(t_{\text {crack }}>t>t_{\text {init }}>t_{0}\right), t_{0}$ is the time (limit state) before crack initiation.

The types of stress intensity factor $K_{i}$ respond to the crack course as follows:

- I. type - critical normal stress $\sigma_{22}$ in axis $X_{2}\left(K_{I}\right.$ for $\left.t: t_{0}<t_{\text {init }}\right)$,

- II. type - critical shear stress $\sigma_{12}$ in a plane $X_{1} X_{2}\left(K_{I I}\right.$ for $t_{\text {init }}$ $\left.: t<t_{\text {crack }}\right)$.

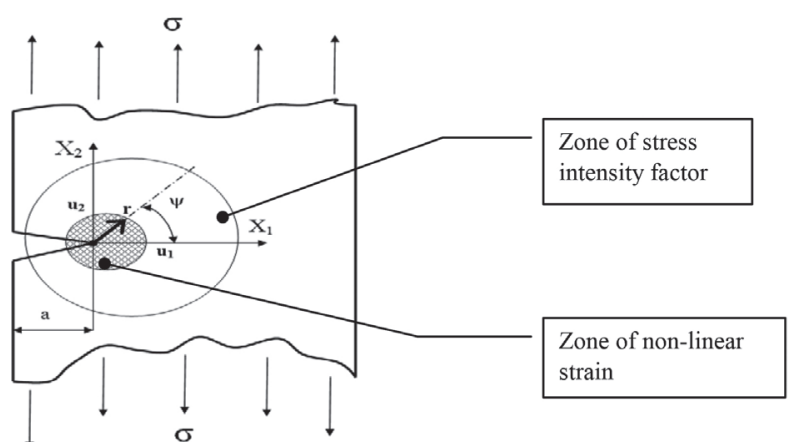

Fig. 3 Crack study with character description of the stress intensity due to the Irwin factor

The initiation of the crack in the sample $t_{\text {init }} \geq t>t_{0}$ is characterized by stress intensity $K_{I}$ and nonzero harmonic stress functions $f_{i j}$. It can be described by the following equations 3-5.

$f_{11}(\Psi)=\frac{1}{\sqrt{2 \pi}} \cos \frac{\psi}{2}\left(1-\sin \frac{\psi}{2} \sin \frac{3 \psi}{2}\right)$,

for $t \geq t_{\text {init }}>t_{0}$

$f_{22}(\Psi)=\frac{1}{\sqrt{2 \pi}} \cos \frac{\psi}{2}\left(1-\sin \frac{\psi}{2} \sin \frac{3 \psi}{2}\right)$,

for $t \geq t_{\text {init }}>t_{0}$

$f_{12}(\Psi)=\frac{1}{\sqrt{2 \pi}} \cos \frac{\psi}{2} \sin \frac{\psi}{2} \sin \frac{3 \psi}{2}$,

for $t \geq t_{\text {init }}>t_{0}$

Then the field of translations is described by the following function $F_{i}$ obtained from equations 6 - 7 .

$F_{1}(\Psi)=\frac{1}{\sqrt{2 \pi}} \cos \frac{\psi}{2}\left(1-2 \mu_{1}+\sin ^{2} \frac{\psi}{2}\right)$,

for $t \geq t_{\text {init }}>t_{0}$ 
$F_{2}(\Psi)=\frac{1}{\sqrt{2 \pi}} \sin \frac{\psi}{2}\left(2-2 \mu_{2}+\cos ^{2} \frac{\psi}{2}\right)$,

for $t \geq t_{\text {init }}>t_{0}$

where $u_{i}$ is the Poisson ratio in longitudinal and transverse directions $_{1,2}$.

The propagation of the crack in the sample follows $t_{\text {crack }}>t>t_{\text {init }}$ and it is characterized by the stress intensity $K_{I I}$ and nonzero harmonic stress functions $g_{i j}(8-10)$.

$g_{11}(\Psi)=-\frac{1}{\sqrt{2 \pi}} \sin \frac{\psi}{2}\left(2+\cos \frac{\psi}{2} \cos \frac{3 \psi}{2}\right)$,

for $t_{\text {crack }} \geq t>t_{\text {init }}$

$g_{22}(\Psi)=-\frac{1}{\sqrt{2 \pi}} \sin \frac{\psi}{2} \cos \frac{\psi}{2} \cos \frac{3 \psi}{2}$,

for $t_{\text {crack }} \geq t>t_{\text {init }}$

$g_{12}(\Psi)=-\frac{1}{\sqrt{2 \pi}} \cos \frac{\psi}{2}\left(1-\sin \frac{\psi}{2} \sin \frac{3 \psi}{2}\right)$,

for $t_{\text {crack }} \geq t>t_{\text {init }}$

Then, the field of translations is described by the following functions $G_{i}$ obtained from equations $11-12$.

$G_{1}(\Psi)=\frac{1}{\sqrt{2 \pi}} \sin \frac{\psi}{2}\left(2-2 \mu_{1}+\cos ^{2} \frac{\psi}{2}\right)$,

for $t_{\text {crack }} \geq t>t_{\text {init }}$

$G_{2}(\Psi)=\frac{1}{\sqrt{2 \pi}} \cos \frac{\psi}{2}\left(-1-2 \mu_{2}+\sin ^{2} \frac{\psi}{2}\right)$,

for $t_{\text {crack }} \geq t>t_{\text {init }}$

\subsection{FEM model of crack propagation in composite textiles}

The FEM model gives not only a description of translation fields and velocity of crack propagation but also stress intensity [7, 9 and 10]. For a calculation of factors $K_{I}, K_{I I}$ Cauchy stress $\sigma_{i j}\left(\sigma_{11}, \sigma_{22}, \sigma_{12}\right)$ and variables $r, \psi$ from the FEM simulation are used. Then, $K_{I}, K_{I I}$ can be expressed by equation (1). The FEM model was created using PAM-CRASH software which can be used for nonlinear mechanical properties of anisotropic materials (hyper elastic, visco-elastic, etc.) [2 and 3]. The principle of the calculation in PAM CRASH is based on an explicit method where the time step of the calculation is solved using central differences. An explicit method allows the solution of shock wave distribution [11]. The advantage of the explicit solution compared to an implicit solution is not only the possibility to study dynamic phenomena but also in its significantly shorter calculation (Figs. 4 and 5). For such complex nonlinear processes as the study of cracks in composite textiles the calculation of an explicit algorithm, which is described by equation (13), has a higher stability than an implicit algorithm, which is described by equation (14). Compared to an implicit solution the explicit solution does not need to calculate the inverse stiffness matrix [12, 13 and 14].

Timing diagram for the displacement, velocity and acceleration of the movement equation: $m \ddot{x}+k x=f(t)$

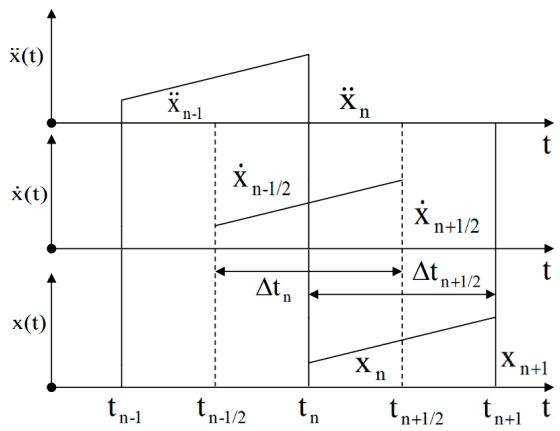

Fig. 4 Explicit solutions

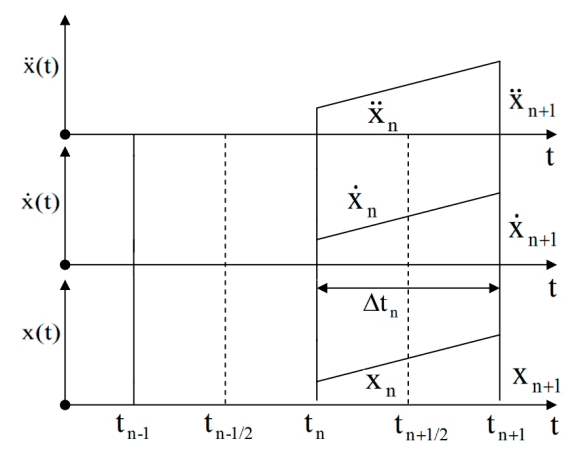

Fig. 5 Implicit solutions

$x_{n+1}=\left(m / \Delta t_{n+1}{ }^{2}+x\right)^{-1} \cdot\left(f_{n+1}-m / \Delta t_{n+1}\left(2 x_{n}-x_{n-1}\right)\right)$ $\mapsto \ddot{\mathrm{x}}_{\mathrm{n}}+\mathrm{kx}_{\mathrm{n}}=\mathrm{fn}$

where the known values are displacement $x_{n}$ in time $t_{n}$ and velocity $\dot{\mathrm{x}}_{\mathrm{n}-1 / 2}$ in time $t_{\mathrm{n}}$. Search values are displacement $\mathrm{x}_{\mathrm{n}+1}$ in time $t_{n+1}$ and velocity $\dot{x}_{n+1 / 2}$ in time $t_{n+1 / 2}$.

$\mathrm{X}_{\mathrm{n}+1}=\mathrm{X}_{\mathrm{n}}+\Delta \mathrm{t}_{\mathrm{n}+1 / 2} \longmapsto \mathrm{m} \ddot{\mathrm{x}}_{\mathrm{n}+1}+k \mathrm{x}_{\mathrm{n}+1}=f_{n+1}$

where the known values are displacement $x_{n}$ in time $t_{n}$ and velocity $\dot{\mathrm{x}}_{\mathrm{n}-1 / 2}$ in time $t_{\mathrm{n}-1 / 2}$. Search values are displacement $\mathrm{x}_{\mathrm{n}+1}$ in time $t_{n+1}$ and velocity $\dot{x}_{n+1 / 2}$ in time $t_{n+1 / 2}$.

It is also possible to study the crack propagation. "Material 150 - Layered Membrane Element” was selected for the material 


\section{COMMNICOIIONS}

Data required for creating the FEM model

Table 2

\begin{tabular}{|c|c|c|c|c|c|c|c|c|}
\hline \multirow{2}{*}{ Model } & \multirow{2}{*}{$\begin{array}{c}\text { Material } \\
\text { model }\end{array}$} & \multirow{2}{*}{$\begin{array}{c}\text { Density } \\
{[\mathrm{kg} . \mathrm{m}-3]}\end{array}$} & \multicolumn{3}{|c|}{ Initial module $\mathrm{E}$} & \multicolumn{3}{c|}{ Shear modulus G } \\
\cline { 4 - 10 } & & & Fibres in MD & Fibres in CD & Matrix & Fibres in MD & Fibres in CD & Matrix \\
\hline Composite textile & 150 & 1052.8 & 1100 & 1300 & 90 & 450.8 & 532.8 & 30.2 \\
\hline
\end{tabular}
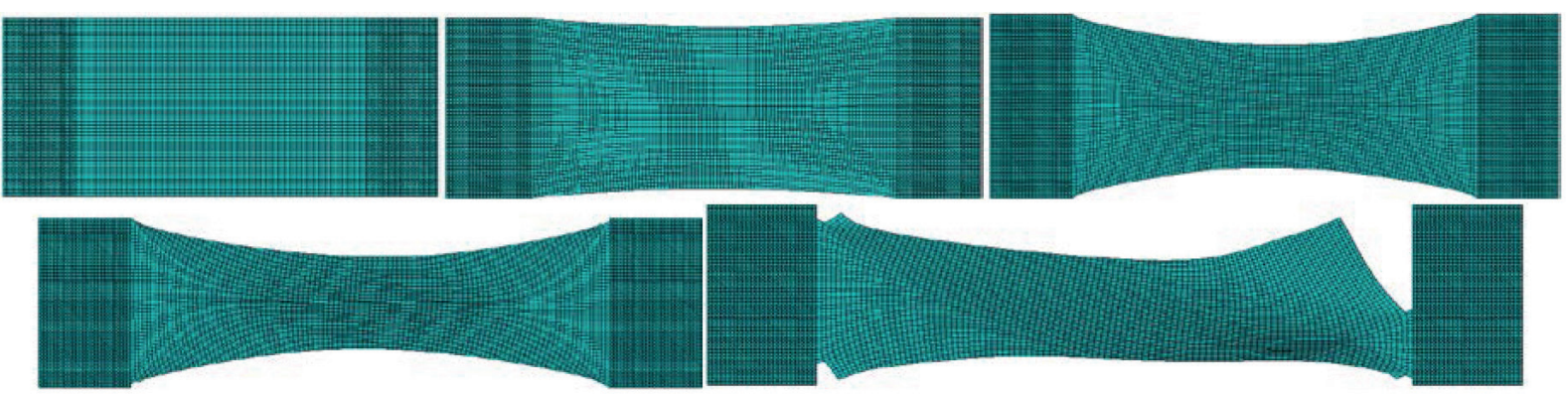

Fig. 6 FEM model of composite textile for studying cracks

model of the composite textile. This model uses 2D membrane elements. It can simulate different mechanical properties of composite textiles in MD (Machine Direction) and CD (Cross Direction) because it allows the material properties for three different layers to be defined including the fibre orientation [2 and 3]. The input parameters of the material model are shown in Table 2. The finite element method mesh (Fig. 6) was created to describe the stress intensity, velocity of crack propagation and especially for the stability of the calculation [6, 8 and 14].

\section{Results and discussion}

The resulting courses of stress intensity factors $K_{I}, K_{I I}$ depending on the ratio $r / a$, are shown in Fig. 7 and the parametric dependence is shown in Fig. 8. A significant difference of stress intensity factors $K_{I}$ and $K_{I I}$ for ductile failure is explained in [6 8]. Comparing the experimental values with the FEM model, the deviation of model was determined as being $9 \%$ (Fig. 9). The size, direction, and visualization of the main crack stress tensor, from which the time-course $\Psi$ can be determined is shown in Figs. 10 and 11 . The maximum value of the principal stress was located at the nodal point of the critical damage of the textile and it reached a value of $17.44 \mathrm{MPa}$. The vectors of velocity and direction of momentum during crack propagation are shown in Figs. 12 and 13 . The velocity of crack propagation in the textile may be influenced by the individual components of the material, the directional orientation of the fibres that affect the orthotrophy, and friction between the fibres. However, the friction is very difficult to measure [15 - 19].
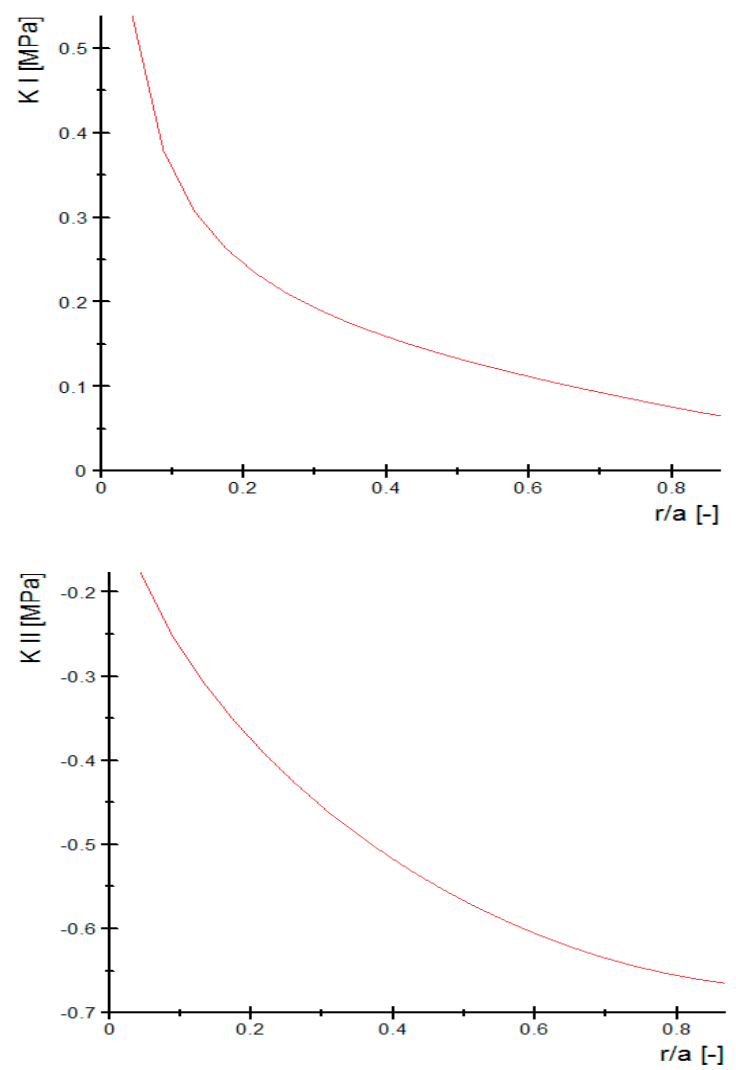

Fig. 7 The dependence of the stress intensity factor $K_{I}, K_{I I}$ on rate $r / a$ 


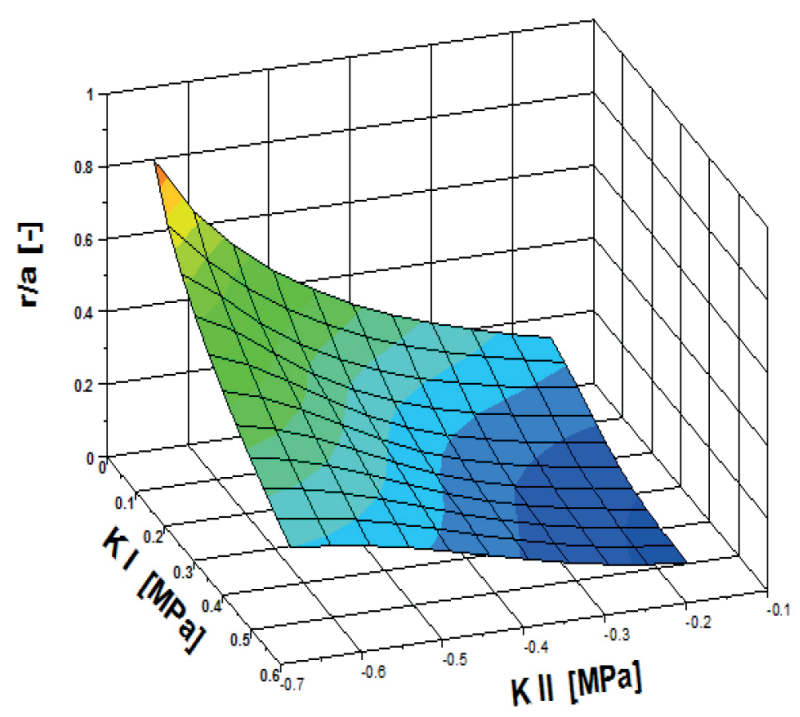

Fig. 8 Parametric dependence $K_{I}, K_{I I}$ on rate $r / a$

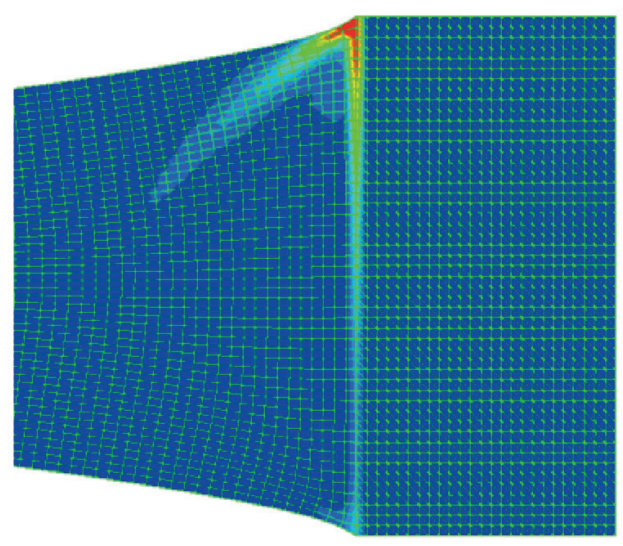

a)
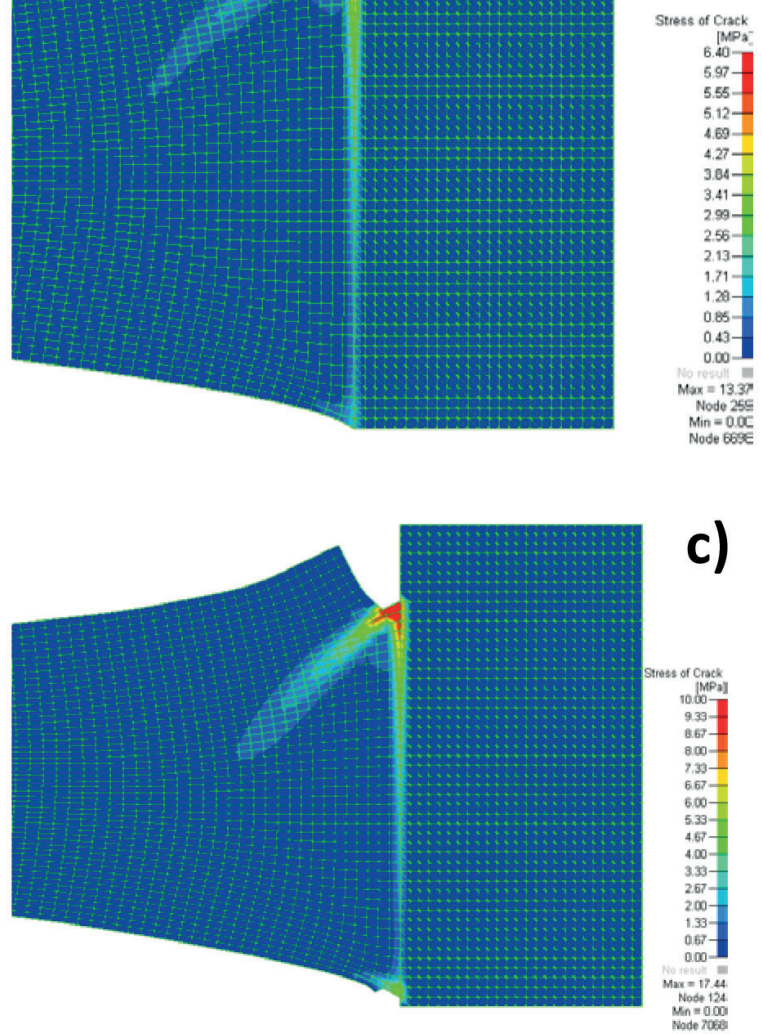

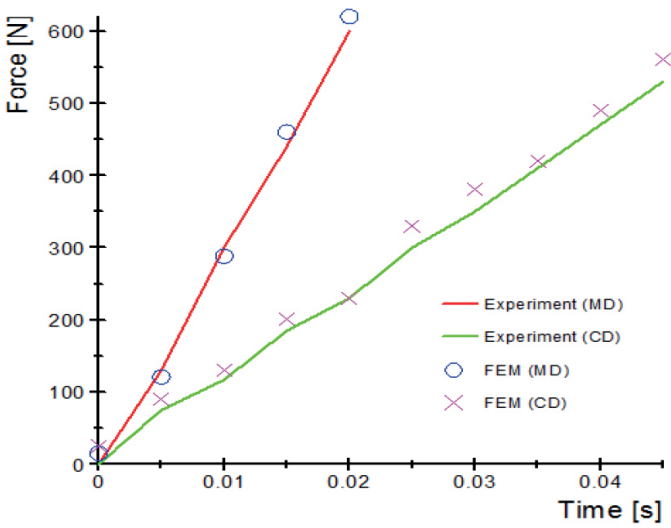

Fig. 9 Comparison of FEM results with the experiment

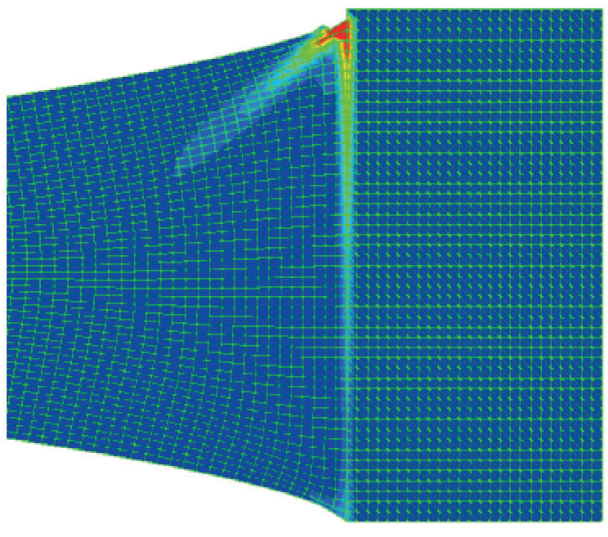

b)
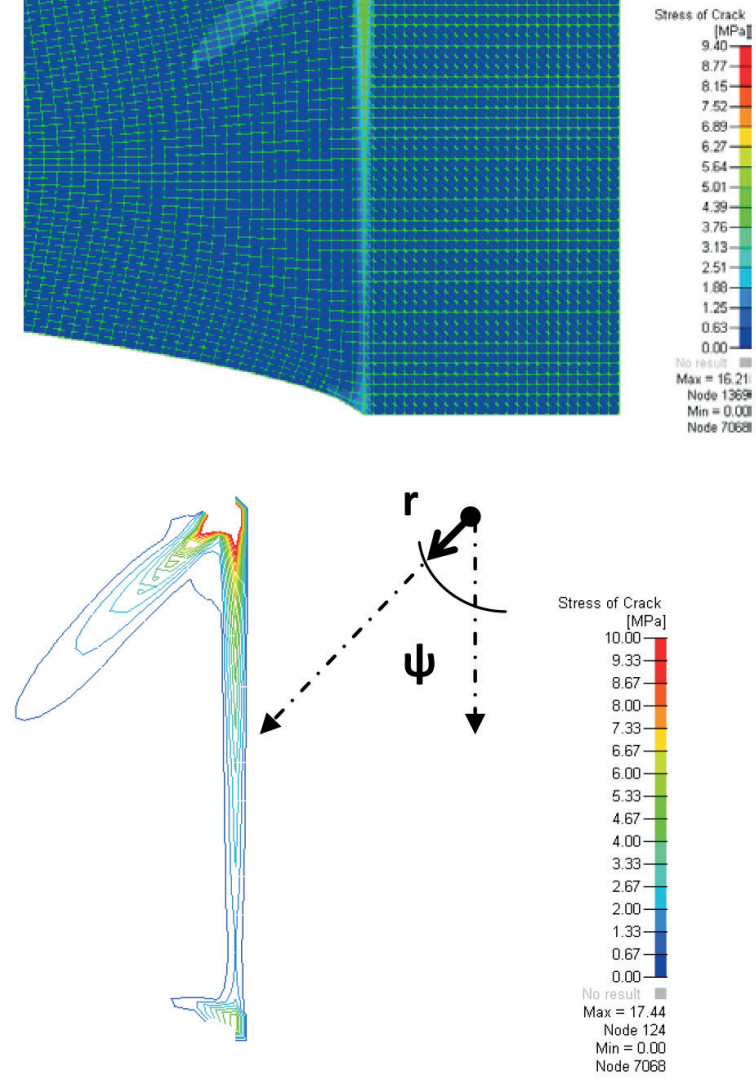

Fig. 11 Distribution of stress intensity: determination of variables $r, \psi$

Fig. 10 Stress intensity in the crack: a) Limit state $\left(t_{\text {init }}>t>t_{0}\right)$; b) crack initiation $\left(t_{\text {crack }}>t>t_{\text {init }}\right)$; c) crack propagation $\left(t=t_{\text {crack }}\right)$ 


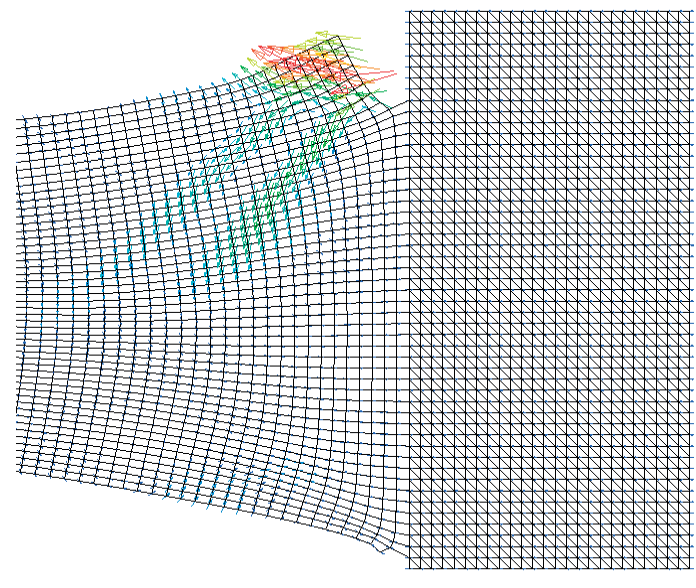

Vector Plot

Fig. 12 Vectors of crack velocity propagation in a composite textile

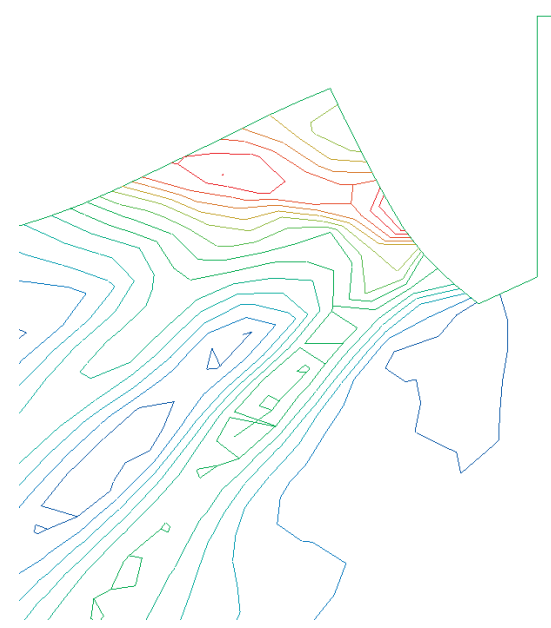

Fig. 13 Distribution of velocity fields in the crack

\section{Conclusion}

This article deals with the description and modelling of crack propagation in a sample of hyper elastic composite textile which could be used as a reinforcing material in car seats. The distribution and intensity of stress in the crack can be described using the Irwin factor based on a continuum where only the crack is solved. The FEM model had significantly nonlinear properties with parameters which are taken from the experiment. The model showed the distribution, initiation and also propagation velocity of the crack in the textile. The model can be used to determine the approximate values of the stress intensity factor in the crack. Thus, the FEM model can help with the study of cracks during fast loading such as during a car accident and it simplifies the optimization process of the material design of different car parts.

\section{Acknowledgements}

The research reported in this paper was supported in part by the Project OP VaVpI Centre for Nanomaterials, Advanced Technologies and Innovation CZ.1.05/2.1.00/01.0005 and the results of this project LO1201 were obtained through co-funding from the Ministry of Education, Youth and Sports as part of targeted support from the "Narodni program udrzitelnosti I" programme and the project "Development of Research Teams of R\&D Projects at the Technical University of Liberec" CZ.1.07/2.3.00/30.0024 and the CREATex project (CZ.1.07/2.2.00/28.0321) which has been financed by the European Social Fund and The Ministry of Education, Youth and Sports of the Czech Republic. This work was supported by the ESF operational programme "Education for Competitiveness" in the Czech Republic in the framework of the project "Support of engineering of excellent research and development teams at the Technical University of Liberec" No. CZ.1.07/2.3.00/30.0065.

\section{References}

[1] SUH, N. P.: Complexity: Theory and Applications (Mit-Pappalardo Series in Mechanical Engineering), Oxford, 2005.

[2] PETRU, M., NOVAK,O., LUFINKA, A.: Study and Analysis of Transmissibility of Car Seat with Non Polyurethane Material, Proc. of 50 $0^{\text {th }}$ Annual Conference on Experimental Stress Analysis, EAN, Tabor, June 2012, 321-326.

[3] PETRU, M., NOVAK, O: Testing and Simulation of Viscoelastic Reinforcement Applied into Car Seat Construction, ACC Journal, No. 17, No. A, Natural Sciences and Technology, 80-88, 2011.

[4] RAGAN, R., KERNOZEK, T. W., BIDAR, M., MATHESON, J. W.: Seat Interface Pressures on Various Thicknesses of Foam Wheelchair Cushions: A Finite Modeling Approach, Archives of Physical Medicine and Rehabilitation, vol. 83, 872-875, 2002.

[5] DUFFY, V. G.: Handbook of Digital Human Modeling - Research for Applied Ergonomics and Human Factors Engineering, Purdue University: Indiana, No. ER564X, 2008.

[6] BITTNAR, Z., SEJNOHA, J.: Numerical Methods in Structural Mechanics, Pitman Monographs and Surveys in Pure and Applied Mathematics, Thomas Telford Publications: London, 1996.

[7] TADA, H., PARIS, C.P., IRWIN G.R.: The Stress Analysis of Cracks Handbook, $3^{\text {rd }}$ ed., Asme Digital Library, 2000.

[8] CRISFIELD, M. A.: Non-linear Finite Element Analysis Solids and Structures, John Wiley \& Sons, 1991. 
[9] KOHAR, R., HRCEK, S., MEDVECKY, S.: Determination of the Maximum Roller Bearing Load with Regards to Durability there of Using Fem Analysis, Communications - Scientific Letters of the University of Zilina, vol. 14, No. 3, 2012, 55-61.

[10] HRCEK, S., KOHAR, R., MEDVECKY, S.: Usage of Dynamic Analysis to Determine Force Interactions between Components of Rolling Bearings, Communications - Scientific Letters of the University of Zilina, vol. 14, No. 3, 2012, 62-67.

[11] PETRU, M., NOVAK, O., HERAK, D., SIMANJUNTAK, S.: Finite Element Method Model of the Mechanical behaviour of Jatropha Curcas L. Seed under Compression Loading, Biosystems Engineering, vol. 111, No. 4, 412-421, 2012.

[12] PETRU, M., NOVAK, O., LEPSIK, P.: Analysis and Measurement of the Charge Intensity of the Selected Electrospinning Electrodes, Applied Mechanics and Materials, vol. 486, 217-222, 2014.

[13] PETRU, M., NOVAK, O., SEVCIK, L., LEPSIK, P.: Numerical and Experimental Research of Design Optimization of Baths for the Production of Nanofibers by the Electrospinning, Applied Mechanics and Materials, vol. 486, 157-162, 2014.

[14] NOELS, L., STAINIER, L., PONTHOT, J. P.: Combined Implicit/explicit Time-integration Algorithms for the Numerical Simulation of Sheet Metal Forming, J. of Computational and Applied Mathematics, vol. 168, 1-2, 331-339, 2004.

[15] BRONCEK, J., DZIMKO, M., HADZIMA, B., TAKEICHI, J.: Experimental Investigations of Aluminium Alloys 2024-t 3 Form in Terms of Tribocorrosion Characteristics, Acta Metallurgica Slovaca, vol. 20, 1, 97-104, 2014.

[16] SAGA, M., DUDINSKY, M., PECHAC, P.: Optimization of Thin Shell Structures using FSD Algorithms, Communications Scientific Letters of the University of Zilina, vol. 14, No. 3, 2012, 32-38.

[17] DEKYS, M., BRONCEK, J.: Measuring Strain of the Lattice Towers, Communications - Scientific Letters of the University of Zilina, vol. 14, No. 3, 2012, 39-42.

[18] HRCEK, S., KRAUS, V., KOHAR, R., MEDVECKY, S., LEHOCKY, P.: Construction of a Bearing Testing Apparatus to Assess Lifetime of Large-scale Bearings, Communications - Scientific Letters of the University of Zilina, vol. 11, No. 2, 57-64, 2009.

[19] HERAK, D., KABUTEY, A., PETRU, M., HRABE, P., LEPSIK, P. SIMANJUNTAK, S.: Relaxation Behaviour of Jatropha Curcas L. Bulk Seeds under Compression Loading, Biosystems Engineering, vol. 125, 2014, 17-23. 